\title{
Picture cube for vision screening of pre-school children
}

\author{
S. W. HYAMS AND E. NEUMANN \\ Department of Ophthalmology, Rothschild Government-Municipal Hospital, Haifa, Israel
}

Fig. I shows a picture cube suitable for vision screening of children from the age of $2 \frac{5}{2}$ years.* The test objects consist of six pictures selected from those designed by Rossano (Fig. 2).

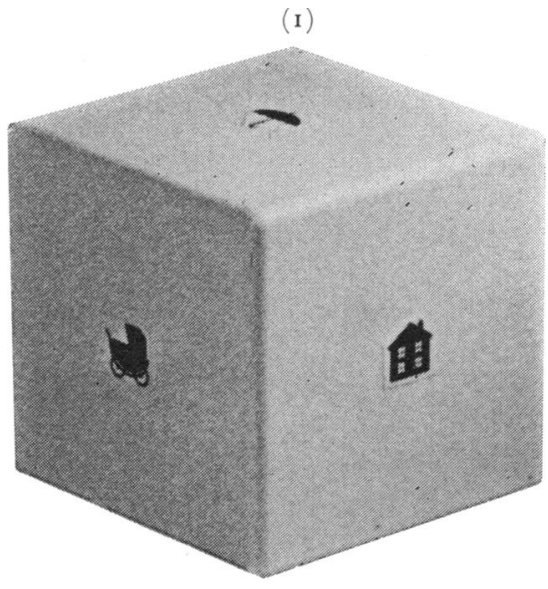

FIG. I Picture cube for screening vision

FIG. 2 The six Rossano pictures used for the picture cube, actual size
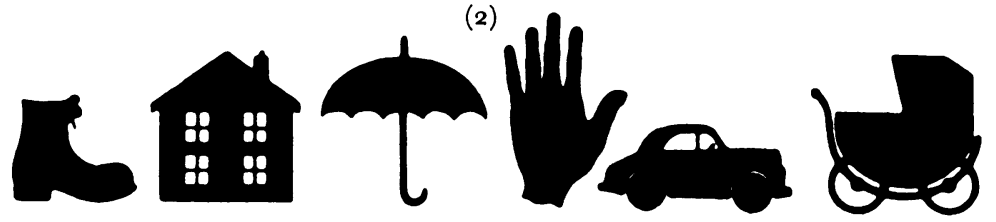

All the pictures are the same size, equivalent to $3 / 7$ Snellen when seen from $3 \mathrm{~m}$ ? Visual acuity, before and after "fogging", was tested with the pictures and with thes illiterate $\mathrm{E}$ in twenty children aged 5 to ro years. It was found that if a child's vision was $3 / 6$ or better with the $\mathrm{E}$ he could identify at least five of the six pictures. If vision was fogged to $3 / 9 \mathrm{E}$, the child could not identify more than four pictures and seldom mor@ than two.

Vision screening with the picture cube is simple and can be performed by the child's nursery school teacher or by any other person with whom the child is familiar. Before the test the examiner asks the child to identify the six pictures. The child is usually able to do this immediately or after only a brief explanation. Vision is then tested fromb three metres, first binocularly and then uniocularly. Some children object to being $\overrightarrow{\mathbb{D}}$ occluded for uniocular testing, but this can be overcome, especially at the nursery schoolo 
by turning occlusion into a game using toy spectacles from which one lens has been removed and the other covered with plaster.

A total of 514 children aged $2 \frac{1}{2}$ to $4 \frac{1}{2}$ years, in twenty nursery schools, were tested with the picture cube; 473 of them saw at least five of the six pictures with each eye when examined by their teacher and a further 24 children saw at least five of the six pictures with each eye when examined by the authors at the Rothschild Hospital. Of the remaining seventeen children, four had myopia, four had astigmatism, and seven had amblyopia in one eye with a visual acuity of $6 / 60$ to $6 / 15$. Only two children could not be examined with the cube due to lack of cooperation.

The authors wish to thank Mr. L. Rose, chief orthoptist at the Hadassah University Hospital, Jerusalem, for his help and advice. 